\title{
ESTRATÉGIAS MENTAIS E DESENVOLVIMENTO COGNITIVO QUE INTERAGEM NO PROCESSO DE ENSINO/APRENDIZAGEM DA MATEMÁTICA
}

\author{
Daniela Soares Santana ${ }^{1}$ \\ Fábio Antônio Sacramento Santana ${ }^{2}$ \\ Telma Regina dos Reis de Assis ${ }^{3}$
}

\begin{abstract}
Resumo
Este artigo apresenta algumas estratégias mentais do desenvolvimento cognitivo que interagem no processo ensino aprendizagem da matemática que deve estar ligado à compreensão do significado: apreender significado de um objeto ou acontecimento pressupõe vê-lo em suas relações com outros objetos e acontecimentos. Grandes mudanças começam a solicitar a reestruturação de todo o sistema de aprendizagem, exigindo novas performances do professor. A metodologia aplicada foi a pesquisa bibliográfica para a coleta de informações. Conclui-se que existem desafios e possibilidades para o processo de ensino aprendizagem da matemática que deve ser minimizado através de um ensino crítico e reflexivo sob o enfoque de oportunidades para que os alunos vivenciem atividades contextualizadas e significativas, objetivando o alcance das múltiplas relações existentes entre a vida dos alunos, em suas necessidades, potencialidades, vivências e desejos e as práticas educativas desenvolvidas na escola.
\end{abstract}

Palavras Chave: Desafios. Ensino. Matemática. Desenvolvimento cognitivo

\begin{abstract}
This article presents some mental strategies of cognitive development that interact in the teachinglearning process of mathematics that must be linked to the understanding of meaning: apprehending the meaning of an object or event presupposes seeing it in its relations with other objects and events. Major changes begin to call for the restructuring of the entire learning system, requiring new performances from the teacher. The applied methodology was the bibliographic research for the collection of information. We conclude that there are challenges and possibilities for the teaching process of learning mathematics that should be minimized through critical and reflective teaching under the focus of opportunities for students to experience contextualized and meaningful activities, aiming at reaching the multiple relationships existing between the lives of students, in their needs, potential, experiences and desires and the educational practices developed at school.
\end{abstract}

Keywords: Challenges. Teaching. Math. Cognitive development

\footnotetext{
${ }^{1}$ Mestre em Ciências da Educação pela Faculdade Interamericana de Ciências Sociales (FICS). Pós graduada em Supervisão Escolar, pela Universidade Federal de Feira de Santana. Pós graduada em Psicopedagogia Clínica e institucional pela Segmento Instituto de Educação. Professora da rede Municipal de Santo Amaro. Coordenadora Pedagógica da rede Municipal de Salvador. Email: daniela.soares.santana@gmail.com

2 Mestre em Ciências da Educação pela Faculdade Interamericana de Ciências Sociales (FICS), Bacharel em Administração pela União das Instituições Educacionais do Estado de São Paulo (UNIESP), Licenciado em Matemática pela Faculdade de Ciências da Bahia (FACIBA). Professor da rede Estadual do Estado da Bahia. E-mail: manggo_17@yahoo.com.br.

${ }^{3}$ Doutoranda em Ciências da Educação pela Faculdade Interamericana de Ciências Sociales (FICS). Mestre em Ciências da Educação pela Faculdade Interamericana de Ciências Sociales (FICS). Especialista em Metodologia e Didática do Ensino Superior pela Faculdade Católica de Ciências Econômicas da Bahia (FACCEBA). Licenciada em Pedagogia Plena pela Faculdade Regional de Filosofia, Ciências e Letras de Candeias (FAC). Licenciada em Matemática pela Universidade Salvador (UNIFACS). Docente pela Secretaria Estadual de Educação de Salvador Ba..Email:telmaassis@rocketmail.com
} 


\section{Introdução}

Atualmente 0 ensino da Matemática se apresenta descontextualizado, inflexível e imutável, sendo produto de mentes privilegiadas. O aluno é, muitas vezes, um mero expectador e não um sujeito partícipe, sendo a maior preocupação dos professores cumprirem o programa.

Os conteúdos e a metodologia não se articulam com os objetivos de um ensino que sirva à inserção social das crianças, ao desenvolvimento do seu potencial, de sua expressão e interação com o meio.

Os estudos e pesquisas das últimas décadas em Educação Matemática e as práticas educativas bem-sucedidas em sala de aula sugerem que os professores de Matemática devem ter em mente alguns princípios.

> A Matemática é uma das mais importantes ferramentas da sociedade moderna;

> A Matemática apropria-se dos conceitos e procedimentos matemáticos básicos contribui para a formação do futuro cidadão, que se engajará no mundo do trabalho, das relações sociais, culturais e políticas;

Aprender Matemática é aprender a resolver problemas. Para isso é preciso apropriar-se dos significados dos conceitos e procedimentos matemáticos para saber aplicá-los em situações novas. Assim "é fundamental que tais conceitos e procedimentos sejam trabalhados com a total compreensão de todos os significados associados a ele" (DANTE, 2002, p.11). Essas são apenas algumas das questões que busca-se compreender neste processo de escrita. Porém sabemos que existem várias formas de estudar matemática com o objetivo de desenvolver o raciocínio lógico. Uma delas é através da resolução de problemas, pois,

Um dos principais objetivos do ensino de matemática é fazer o aluno pensar produtivamente e, para isso, nada melhor que apresentar-Ihe situaçõesproblema que o envolvam, o desafie e o motivem a querer resolvê-las (Ibid., p.11).

Desta forma, pretende-se conhecer e dialogar com pensadores, leis e o público a ser estudado visando ampliar a discussão para que novos questionamentos possam ser criados e novas propostas possam ser fomentadas acerca do ensino e do estudo da matemática uma vez que é a principal motivação para esta pesquisa. 


\section{Principais Teorias Aplicadas Para o Ensino da Matemática}

Em sua teoria denominada "Epistemologia Genética" Piaget baseia-se em pesquisas feitas por mais de 50 anos, sua vida foi dedicada a análise do processo de obtenção do conhecimento humano. Piaget partiu de pesquisas pautadas no desenvolvimento infantil para explicar como o homem consegue alcançar níveis de conhecimento mais avançados.

A origem do pensamento infantil foi seu ponto de partida para chegar a consciência do adulto, quando o pensamento fica mais elaborado. Outra teoria nos referencia neste estudo é a sócio interacionista de Vygotsky preconiza que o ensino se dá por meio da interação social, ou seja, o desenvolvimento cognitivo e consequentemente $o$ aprendizado em matemática pode ser mais produtivo por meio de atividades em grupo, trocas de experiências entre alunos e aluno e professor. A aprendizagem e o desenvolvimento intelectual partem da interação social.

As teorias desenvolvidas por Piaget nos trazem situações fundamentais que contribuem para o "método" de ensino da matemática. Piaget buscou identificar as fases de transição do conhecimento, abrangendo a passagem dessas fases desde 0 conteúdo mais simples para um conteúdo mais complexo. Tais fases receberam o nome de estágios, que, consistem no desenvolvimento do raciocínio lógico. Segundo a teoria de Piaget (1990) o ser humano para atingir sua capacidade plena de raciocínio, o desenvolvimento infantil passa por quatro estágios demonstrados no Quadro 1.

Quadro 1 - Estágios De Desenvolvimento Infantil

\begin{tabular}{|l|l|l|}
\hline \multicolumn{1}{|c|}{ ESTÁGIO } & \multicolumn{1}{|c|}{ IDADE } & \multicolumn{1}{c|}{ CONCEPÇÃO } \\
\hline Sensório motor & (0 a 2 anos) & $\begin{array}{l}\text { Inteligência prática, noções de tempo e } \\
\text { espaço construídas com o meio como } \\
\text { exemplo. }\end{array}$ \\
\hline Pré-operatório & $\begin{array}{l}\text { Inteligência simbólica, aquisição de } \\
\text { linguagens como forma de expressão. }\end{array}$ \\
\hline Operatório-concreto & (7 aos 12) & $\begin{array}{l}\text { Desenvolvimento da noção de espaço e } \\
\text { tempo, capacidade de abstração da } \\
\text { realidade }\end{array}$ \\
\hline Lógico-Formal & $\begin{array}{l}\text { Já pensa em relações baseadas em } \\
\text { hipótese, abstração total. }\end{array}$ \\
\hline
\end{tabular}

Fonte: Piaget (1990)

Para Piaget o conhecimento se faz a partir de construções contínuas e renovados por uma interação com o mundo real, essas construções são resultados de interpretações que temos através das experiências de vida que são particulares, como as pessoas não são iguais não podem ter experiências iguais e cada 
experiência proporciona um aprendizado. O professor deve ser o facilitador de experiências e estimulador, os erros devem ser respeitados pois fazem parte do processo de elaboração do conhecimento.

As pessoas precisam aprender para se manter em equilíbrio, para o autor quando não entendemos algo uma das reações é a negação. Para Piaget a aprendizagem se destina ao processo de ajustamento do meio e está composto por dois mecanismos: assimilação e acomodação, que são regulados pelo processo de equilibração e:

Pode dizer-se que toda necessidade tende, primeiro a incorporar as pessoas e as coisas na atividade própria do sujeito, portanto a 'assimilar' o mundo exterior as estruturas construídas, e segundo, a reajustar estas em função das transformações sofridas, portanto em "acomoda-las" aos objetos externos (PIAGET, 1990, p. 17).

As ações e as experiências logico-matemáticas concretas precisam de uma elaboração para atingir a evolução do espirito dedutivo, porque as operações mentais precisam das experiências internalizadas, pois estas internalizações permitem a abstração. Pode-se destacar que:

\begin{abstract}
A maioria das crianças de seis a nove anos ainda não possuem o pensamento operatório concreto estabilizado, somente $11,2 \%$ das crianças estudadas demonstram ter construído as operações logicas características deste nível, enquanto que as restantes ou apresentam características do pensamento pré-operatório ( $8 \%$ ) ou estão no período de construção dessas estruturas (78,8\%) (FREITAG, 1984, p. 10).
\end{abstract}

Percebe-se diferenças neste processo de construção das estruturas operatórias, nota-se que algumas crianças, evoluem mais que outras. De acordo com a teoria psicogenética de Piaget, a interação no meio que vivem, possibilita uma ação reflexiva mais ou menos intensa, dando equilíbrio ao processo de desenvolvimento. A forma como se relacionam com os adultos nos primeiros anos de vida é fundamental, pois através das provocações e desafios, a criança poderá se desenvolver. Os adultos precisam incentivar as crianças nesta fase demonstrando-Ihes confiança e afeto na capacidade de aprendizado delas.

O conhecimento lógico-matemático é uma construção feita pela criança a partir de suas experiências mentais acerca do mundo, essas construções são relacionadas com os seus pensamentos e as ações sobre os objetos, sua sensibilidade de acordo com o seu mundo e suas experiências.

Durante muito tempo a escola tradicional utilizou a repetição, memorização e a verbalização, essa metodologia foi criticada por Piaget, pois a criança não deveria ser considerada um 'ser passivo', vazio. Piaget defendia o ensino para formar o 
raciocínio, conduzindo a compreensão e não a reprodução ou memorização, desenvolvendo a criticidade e criatividade.

O docente deve buscar métodos que permitam o discente encontrar a solução correta de acordo com seu nível de desenvolvimento psicogenético, por meio de trabalhos práticos, individuais ou em grupo, da conversa entre professor e aluno ou entre colegas.

A matemática é tratada na maioria das vezes como a disciplina que só transmite um conjunto de formulas, regras, signos sem assegurar o desenvolvimento e entendimento da capacidade de aprender, o seu ensino é quase todo voltado para a memorização de 'regras' e 'truques' que na maioria das vezes não obtemos a compreensão dos porquês, porém utilizamos porque 'funcionam'.

Tendo a matemática como princípio norteador, Piaget desenvolveu teorias baseadas em tal disciplina. Por meio dos seus estudos ele procurou diagnosticar as fases de transição de conhecimentos abrangendo a passagem de um conteúdo mais fácil para um mais complexo. Os estágios baseiam-se na capacidade de desenvolvimento do raciocínio lógico. Para Piaget a matemática é o resultado do processo mental da criança em relação ao dia a dia. Os fundamentos para Piaget sobre a educação levam em consideração a evolução da psicologia, biologia, medicina, filosofia e antropologia.

\section{Principais Metodologias no Ensino da Matemática}

O estudo dos melhores métodos praticados em uma determinada área é denominado de metodologia. Na área de ensino existem diferentes métodos, os principais aplicados no Brasil são os Métodos Montessoriano 4 (de Maria Montessori) e o tradicional (conteudista). Para cada área existe uma metodologia, que "é o campo em que se estudam os melhores métodos praticados em determinada área para a produção do conhecimento" (OLIVEIRA, 2007, p. 47 e 48). Método é a maneira para alcançar um fim determinado.

A metodologia desenvolvida pela psiquiatra Maria Montessori tem seu foco no desenvolvimento infantil holístico, as ênfases são uma aprendizagem por meio de experiências concretas e não apenas através de teorias. Sua contribuição para a metodologia do ensino da matemática foi fundamental. Na sala de aula Montessori,

\footnotetext{
4 Resultado de pesquisas científicas e empíricas desenvolvidos pela médica e pedagoga Maria Montessori. É caracterizado por uma ênfase na autonomia, liberdade com limites e respeito pelo desenvolvimento natural das habilidades físicas, sociais e psicológicas da criança.
} 
pesos, medidas, quantidades e outros conceitos da matemática são ensinados com a assistência de materiais e recursos concretos, à medida que a criança desenvolve seu raciocínio logico e o pensamento abstrato esses materiais ficam mais complexos.

A matemática é um conjunto de regras e o conhecimento é cumulativo, na medida que os conhecimentos vãos sendo solidificados o nível de complexidade vai aumentando. Os materiais multissensoriais, fazem uma junção entre objetos e movimentos e situações matemáticas. A manipulação de blocos, barras, placas, cubos fazem as crianças entenderem os formato, tamanho, quantidades e proporções.

A metodologia Montessori proporciona a criança aprender conceitos matemáticos com objetos e experiências concretas, ou seja, na prática, essa metodologia possibilita o desenvolvimento das competências necessárias para a compreensão das abstrações e a realização de operações mentais (SILVA e ARAUJO, 2011).

A interação concreta e não apenas teórica, facilitava o aprendizado e o desenvolvimento da capacidade cognitiva. Sua metodologia se assemelha com as teorias de desenvolvimento matemático do homem primitivo, principalmente quando o homem começou a entender na pratica os conceitos de conjunto, tamanho, quantidade, forma por meio de grupos, tamanhos, formas e quantidades de animais, arvores, pedras e o que era essencial para sua sobrevivência.

A psiquiatra descobriu por meio de seus estudos científicos o aprendizado através das experiências concretas e múltiplos sentidos, o homem primitivo seria a criança na sala de aula Montessori aprendendo intuitivamente com objetos e situações praticas permitindo sentir, pegar e ver objetos com tamanho, forma e suas quantidades, e "a persistência da raça humana provavelmente tem relação com o desenvolvimento no homem, de conceitos matemáticos" (lbid. p.1).

As salas bem organizadas e as matérias arrumadas seguindo uma lógica para facilitar o movimento das crianças, que podem utiliza-los de forma autônoma e após o uso coloca-los em seus respectivos lugares. Manter os objetos organizados incentiva a criança a organizar seus processos cognitivos internos, a matemática requer organização, continuidade e o uso correto das suas regras.

Em contrapartida a metodologia supracitada, o ensino da matemática ainda em muitos lugares está sendo baseado no ensino tradicional (conteudista), voltado 
para a memorização, rigorosidade e a punição, o aluno, uma espécie de papel em banco recebendo 'depósitos' de conhecimento do professor.

O ensino tradicional utiliza métodos onde o processo de ensino se dá por meio de hereditariedade e maturidade do raciocínio, deixando de lado o frescor das interações socioculturais na formação das estruturas cognitivas dos discentes. Esse tipo de aula não permite ao educador o desafio, e muito menos se coloca para o crescimento individual, fica restrito ao que é ensinado, e o aluno tem sua capacidade de desenvolvimento limitada, o ensino tradicional praticamente trata o educando como um elemento que nada sabe inclusive sem levar em conta o seu conhecimento prévio.

O modelo de ensino tradicional considera o aluno que chega, como alguém que não sabe nada e que não possui conhecimento prévio sobre a matemática é considerado vazio, pois:

\footnotetext{
O educador, que aliena a ignorância, se mantém sempre em posições fixas, invariáveis. Será sempre o que sabe, enquanto os educandos serão sempre os que não sabem. A rigidez destas posições nega a educação e o conhecimento como processo de busca (FREIRE, 1987, p.34).
}

No decorrer de uma aula de matemática, durante a resolução de problemas o professor pode ajudar a despertar no aluno o gosto pela matéria, os desafios envolvidos na resolução e as estratégias encontradas aumentam a capacidade de raciocínio, incentiva a curiosidade, a criticidade na busca do conhecimento.

O professor precisa pesquisar aprender para utilizar de metodologias e conteúdo que ajudem no processo educacional. A matemática ensinada de maneira tradicional traz o professor como transmissor e o aluno apenas como mero ouvinte/receptor das informações e mero executor das atividades realizadas mecanicamente e inúmeras vezes até que o aluno memorize, porém nem todos conseguem memorizar.

O ensino mecânico não contempla as relações do indivíduo com o cotidiano, suas interações sociais e as trocas de experiências, a valorização é dada ao trabalho individual, a concentração, o esforço e a disciplina como garantia de obtenção do conhecimento. As trocas de informações, questionamentos, dúvidas, a comunicação e interação entre colegas não é permitida sendo interpretado como indisciplina e falta de respeito. 
O professor é o único que pode interagir com o aluno, o docente é o responsável por direcionar, punir e treinar, sendo a aprendizagem confundida com a memorização sem o senso crítico. Vale destacar que:

Não há ensino sem pesquisa e pesquisa sem ensino. Esses que fazeres se encontram um no corpo do outro. Enquanto ensino continuo buscando, reproduzindo. Ensino porque busco, porque indaguei, porque indago e me indago. Pesquiso para constatar, constatando, intervenho, intervindo educo e me educo. Pesquiso para conhecer o que ainda não conheço e comunicar ou anunciar a novidade (FREIRE, 1996, p.14).

Escolher qual metodologia que melhor se encaixa em um determinado grupo não é uma tarefa fácil, existem grupos em que a amplitude entre os saberes é grande e o professor como já foi mencionado precisa pesquisar, criar estratégias para obter um ambiente propicio em que exista a interação sem causar constrangimento aos alunos.

Preocupar-se com a didática é estabelecer os vínculos entre o ensino e a aprendizagem, ou seja, o processo pedagogização ${ }^{5}$ do saber cientifico. A matemática é um tipo de conhecimento universal, um corpo de conhecimento desenvolvido pelo homem independente do componente local, ela ocorre em todas as culturas, em todos os momentos históricos encontramos elementos inerentes ao que chamamos hoje de matemática, atividades como medir, contar, quantificar, classificar, explicar, generalizar, inferir, prever fatos, fazem parte da história da humanidade.

\begin{abstract}
Muito já foi dito sobre a universalidade da ciência. Esse conceito de universalidade parece não ser fácil de manter, como mostram pesquisas recentes levadas a efeito por antropologistas que mostram praticas tipicamente cientificas tais como, observar, contar, ordenar, escolher, medir, pesar, efetuadas de um modo mais radical do que aquelas comumente ensinadas nos sistemas escolares. Essas observações encontravam estudos posteriores sobre a evolução dos conceitos científicos e práticas matemáticas numa estrutura antropológica e cultura (SANTOS, 2007, p. 270).
\end{abstract}

Algum país tem conseguido maior êxito no Programa Internacional de Avaliação dos Alunos ${ }^{6}$ - PISA, que realiza uma avaliação internacional que mede o nível educacional de jovens por meio de provas de leitura, matemática e ciências e

\footnotetext{
${ }^{5}$ Efeito prático de emprestar um caráter de ensino a determinada ciência, ato ou conceito, no sentido de torná-lo uma ferramenta passível de uso transformador de uma dada realidade.

${ }^{6}$ É um estudo comparativo internacional, realizado a cada três anos pela Organização para a Cooperação e Desenvolvimento Econômico (OCDE) que oferece informações sobre o desempenho dos estudantes na faixa etária dos 15 anos, vinculando dados sobre seus backgrounds e suas atitudes em relação à aprendizagem e também aos principais fatores que moldam sua aprendizagem, dentro e fora da escola.
} 
seu principal objetivo é produzir indicadores que contribuam dentro e fora dos países participantes para a discussão da qualidade da educação básica e que possam subsidiar práticas nacionais de melhoria da educação.

\section{Estilos de Aprendizagem}

Entendendo o conceito das inteligências múltiplas pode-se então buscar uma melhor estratégia para o ensino/aprendizagem. Existem pessoas que se adaptam a determinado estilo de aprendizagem que são rasgos cognitivos, afetivos e psicológicos, que servem como indicadores relativamente estáveis de como os alunos percebem, interagem e respondem aos seus ambientes de aprendizagem.

Os estilos de aprendizagem são:

As formas de como os alunos assimilam e processam as informações que auxiliam na construção do seu conhecimento. Identificar os diferentes estilos de aprender de cada aluno proporciona ao professor adequar sua prática pedagógica para que contemple as diferentes formas de aprender presentes em sua sala de aula (CUNHA e GOMES FIGUEIREDO, 2016, p.2).

No ambiente escolar mais precisamente em sala de aula, a diversidade de estilos de aprendizagem abrange o modo como os estudantes optam por perceber, reter, processar e organizar o conhecimento. Refletir sobre os diferentes meios de aprender que existem atualmente, requer que respeitemos as individualidades $\mathrm{e}$ diversidades de cada indivíduo (BARROS e LEHFELD, 2007).

A partir disso, são desenvolvidas teorias que possibilitam uma maior inclusão no processo de ensino/aprendizagem, pois "o ato de aprender é individual frente ao sujeito que aprende da forma como pode, no seu tempo e no seu ritmo" (PEREIRA, 2010, p. 9).

\section{VARK - Teoria Visual, Auditivo, Leitura/Escrita e Cenestésico}

Essa teoria surgiu através do estudo de Neil Fleming em 1992, que defende a ideia de quatro canais de aprendizado para o ser humano. De acordo com Neil Fleming as estratégias de aprendizagem de acordo com o estilo apresentados na Quadro 2 podem ajudar no conhecimento se forem identificados previamente e trabalhados de acordo com suas afinidades apresentadas. 
Quadro 2 - Descrição das Estratégias de Aprendizagem Para o Estilo de Aprendizagem - VARK

\begin{tabular}{|l|l|}
\hline \multicolumn{1}{|c|}{ ESTILO } & \multicolumn{1}{c|}{ DESCRIÇÃO } \\
\hline Visual & $\begin{array}{l}\text { As pessoas com esse perfil tem uma maior facilidade para aprender através de } \\
\text { materiais visuais, são mais estimulados através de gráficos, tabela, mapas } \\
\text { mentais, listas. Eles preferem utilizar listas para organizar o raciocínio e os } \\
\text { pensamentos. Tem facilidade para lembrar-se da fisionomia das pessoas, porém } \\
\text { esquecem seus nomes. Distúrbios sonoros geralmente não tiram sua } \\
\text { concentração, porém se distraem com movimentações. }\end{array}$ \\
\hline Auditivo & $\begin{array}{l}\text { Ouvir podcasts, música, aulas expositivas, palestras, bate papos são formas de } \\
\text { aprendizagem preferidas para esse tipo de perfil, as instruções faladas } \\
\text { proporcionam uma maior assimilação. Se distraem mais facilmente por sons. Eles } \\
\text { geralmente gostam de perguntar e repetir as informações em voz alta para } \\
\text { memorizar. }\end{array}$ \\
\hline Leitura/escrita & $\begin{array}{l}\text { Esse perfil tem maior facilidade na leitura e transmissão de ideias através de } \\
\text { redações, gostam de tomar nota dos assuntos durante as atividades como } \\
\text { palestras, aulas e seminários. Preferem de desenhar planos e esquema para } \\
\text { lembrar os conteúdos. }\end{array}$ \\
\hline Sinestésico & $\begin{array}{l}\text { Estímulos externos só essenciais para que os conteúdos sejam fixados. Esse } \\
\text { perfil prefere aprender realizando tarefas por si sós. São pessoas que utilizam } \\
\text { muito o toque, as atividades concretas, as dinâmicas, as demonstrações e } \\
\text { simulações para melhor assimilação dos assuntos, conteúdos e informações. }\end{array}$ \\
\hline
\end{tabular}
Fonte: Ferreira, 2014

As Estratégias de Aprendizagem Para o Estilo de Aprendizagem apresentadas na recomendam que o educador deve aproveitar as distintas formas de estratégias na sala de aula para atingir o objetivo do aprendizado incentivando o desenvolvimento em todas as dimensões para elevar ao máximo o aprendizado. Vale salientar que é um interessante recurso para auxiliar a aprendizagem que o professor identifique os diversos estilos de aprendizagem entre os estudantes.

Para auxiliar nesse processo de aprendizagem a Quadro 3, faz uma relação das técnicas de ensino e estilos de aprendizagem que podem ser utilizadas para uma melhor absorção do conteúdo.

\begin{tabular}{|c|c|c|c|}
\hline VISUAL & AUDITIVO & LEITURA/ESCRITA & SINESTÉSICO \\
\hline Diagramas & Debates, Palestras & Livros, textos & Estudos de caso \\
\hline Gráficos/imagens & Conversas & Folhetos & Modelos de trabalho \\
\hline Aula expositiva & CDs de áudios & Leituras de artigos & Palestrantes convidados \\
\hline Vídeos & Áudio e vídeo & $\begin{array}{l}\text { Comentários } \\
\text { escritos }\end{array}$ & Demonstrações \\
\hline Resolução de exercícios & Seminários & $\begin{array}{l}\text { Desenvolvimento } \\
\text { de resumos }\end{array}$ & Atividades físicas \\
\hline Pesquisa de internet & Música & Ensaios & Resolução de exercícios \\
\hline Aulas práticas & Discussões & Múltipla escolha & Palestras \\
\hline Projeções (slides) & Dramatização & Bibliografia & Aulas Práticas. \\
\hline
\end{tabular}

Fonte: Fleming,(2001)

As técnicas de ensino para esse tipo de aprendizagem podem ser utilizadas estrategicamente desde que sejam identificados qual a maior afinidade que o aluno tem com o estilo descrito. Para estudantes com dificuldade em matemática o 
professor terá que planejar sua aulas de acordo com as identificações de cada grupo, porque:

O grande desafio que se encontra na educação é, justamente, habilitar o educando a interpretar as capacidades e a própria ação cognitiva de cada individuo, não da forma linear, estável e continua, como é característico das práticas educativas mais correntes" (DAMBROSIO,2013,p.59).

Se o aluno tem maior facilidade em aprender visualmente, as aulas com exemplos no quadro, desenho de formulas e exposições visuais com os exemplos práticos podem ajudar no ensino/aprendizagem. Se o aluno tiver o estilo auditivo, paródias podem ser criadas, por exemplo, sobre as razões trigonométricas ${ }^{7}$ debates e seminários podem ser desenvolvidos pelos alunos através da exposição dos assuntos.

O aluno que se identifica com a leitura e escrita pode ter maior apreço pela matemática e desenvolver maior afinidade a partir do estudo histórico da matéria e os fatos que deram origem as formulas e o pensamento matemático. $O$ sinestésico precisa de uma abordagem mais concreta, trabalhos manuais com sólidos geométricos, atividades e dinâmicas que permitam realizar exercícios de medição de volumes, áreas e tenham comprovação práticas podem ajudar também no ensino aprendizagem.

O estilo de ensino desenvolvido por Fleming possibilita quatro abordagens de acordo com a afinidade do aluno, pois a matemática precisa sair do pedestal, ser mais atrativa, se encaixar no interesse do educando, pois "o currículo dinâmico reconhece que nas sociedades modernas as classes são heterogêneas, reconhecendo-se entre os alunos interesses variados e enormes gama de conhecimentos prévios" (DAMBROSIO, 2009, p.89). Como os indivíduos são diferentes uns dos outros, logo as experiências, afinidades e percepções também são diferentes.

\section{Kolb - Teoria da Aprendizagem Experimental}

A Teoria da Aprendizagem Experimental (TAE) foi desenvolvida pelo professor David Kolb em 1984, essa teoria pressupõe que as pessoas possuem diferentes estilos de aprendizagem influenciada de acordo como o individuo percebe e processa a realidade. A Teoria da Aprendizagem Experimental utiliza:

\footnotetext{
${ }^{7}$ São relações entre os lados de um triângulo retângulo que resultam da divisão entre as medidas dos seus lados.
} 
A experiência como centro do aprendizado, isto é, o modo como as pessoas adultas aprendem e se desenvolvem. $O$ aprendizado requer que os indivíduos desenvolvam habilidades que estão em polos opostos. A decisão de como o indivíduo quer aprender depende de sua escolha pessoal: alguns obtêm informações de experiências concretas e tangíveis, enquanto outros de representações abstratas, planejando, pensando ou analisando determinada situação (KRAKAUER; APARECIDO DOS SANTOS; RIBEIRO DE ALMEIDA, 2017, p.7).

Essa abordagem tem como base teórica o modelo da aprendizagem centrado na pessoa e que propicia o desenvolvimento da autonomia do aprendizado, onde "o respeito a autonomia e a dignidade de cada um é um imperativo ético e não um favor que podemos ou não conceder uns aos outros" (FREIRE, 1996, p.25).

$O$ aluno através das suas experiências percebe suas limitações e qualidades tem maior liberdade sentem-se mais seguros para fazer suas escolhas. Essa teoria possui quatro estágios:

> Experiência concreta - A aprendizagem pela experiência concreta permite que as pessoas envolvidas em uma determinada atividade ou experiência aprendam a partir da maneira como se sentiram. Essas pessoas geralmente acham abordagens teóricas irrelevantes, preferindo aprender por meio de exemplos específicos e práticos.

> Observação reflexiva - A aprendizagem pelo processamento utiliza uma experiência concreta como base, o individuo aprende baseando-se em observações e julgando as mesmas, para poder aprofundar sua compreensão.

> Conceitualização abstrata - A aprendizagem pela generalização é baseada no reflexo de uma experiência que gera novas informações, esse aprendizado é analítico e conceitual, e se apoia inclusive no raciocínio-lógico.

> Experimentação ativa - A aprendizagem pela atuação indica uma grande disposição em executar atividades práticas. São indivíduos que preferem projetos práticos, discussões em grupo.

Pode-se afirmar de acordo com os o estágios apresentados acima os alunos tem maior afinidade e relacionam-se melhor com os colegas do que com uma autoridade ou até mesmo com o professor. Esses alunos preferem assistir aulas através das observações e julgamentos porque eles aprendem mais, e geralmente são pessoas mais introvertidas. Os alunos aprendem melhor através da teoria e da 
analise minuciosa e sistemática e eles não gostam de aulas passivas, preferem as aulas dinâmicas e participativas.

\section{O lúdico como estratégia de ensino}

Aprender matemática precisa ser uma experiência agradável e que traga fascínio pelos assuntos, desafios matemáticos eram realizados em praça publica na idade média com direito a premiações.

As atividades matemáticas podem ser realizadas através de jogos pois desde que Froebel introduziu os jogos no centro da educação matemática, os professores podem estimular os seus alunos através de atividades voltadas para o desenvolvimento do raciocínio lógico, da criatividade, da capacidade de resolver diferentes tipos de problemas. Os jogos podem ser encarados pelos alunos como um divertimento, mas que se bem empregados podem ajudar no ensino/aprendizagem da matemática, pois:

O jogo para ensinar matemática deve cumprir o papel de auxiliar no ensino do conteúdo, propiciar aquisição de habilidades, permitir o desenvolvimento operatório do sujeito e, mais, estar perfeitamente localizado no processo que leva o aluno do conhecimento primeiro ao conhecimento elaborado. (MOURA, 1992, p.47)

Partindo do principio que todos os jogos possuem regras, o mesmo conceito deve ser aplicado na matemática, por exemplo: para resolver uma expressão numérica precisamos seguir uma ordem (regras), o objetivo do 'jogo' é encontrar o valor final, resultado, para tal é necessário seguir as instruções sem violar as regras, primeiro devemos resolver a potenciação/radiciação, segundo multiplicação/divisão, terceiro soma/adição.

Caso a expressão apresente mais de uma operação com prioridade, deve-se resolver a partir da esquerda para a direita o que aparecer primeiro.

Exemplo:

a) $87+7.85-120=$

$87+595-120=$

$682-120=562$

b) b) $25+62: 12-\sqrt{ } 169+42=$

$25+36: 12-13+42=$

$25+3-13+42=$

$28-13+42=$

$15+42=57$ 
É possível classificar três tipos de jogos a serem utilizados no ensino/aprendizagem em matemática, jogos estratégicos que podem ser desenvolvidas as habilidades logico-matemáticas. Através das regras os alunos buscam o melhor caminho para atingir o objetivo final através de estratégias, pois:

Acredita-se que no processo de desenvolvimento de estratégias de jogo o aluno envolve-se com o levantamento de hipóteses e conjecturas, aspecto fundamental no desenvolvimento do pensamento cientifico, inclusive matemático (D’AMBROSIO, 1989, p.5).

Jogos de treinamento possibilitam o professor conhecer os alunos que precisam de reforço em um determinado assunto e prefere não utilizar as listas de exercícios cansativas e os jogos geométricos que desenvolvem a observação e o raciocínio lógico, permite o trabalho com figuras geométricas, semelhança de figuras, ângulos e polígonos.

Os jogos digitais podem englobar as três classificações, pois através deste novo conceito dos 'games' os conteúdos pode ser trabalhado de forma rápida e significativa além de ajudar na conexão com outras áreas do conhecimento, potencializando a capacidade de compreensão dos conceitos matemáticos.

$\mathrm{O}$ ambiente virtual proporciona ao aluno vivenciar e experimentar os erros além de poder buscar o conhecimento de maneira mais ágil, desenvolve o raciocínio-lógico, estratégico a capacidade de raciocínio dedutivo, resolvendo problemas e encontrando soluções e percebendo como é prazeroso aprender matemática e "o aprender e gostar estão diretamente relacionados à forma pela qual é planejada e utilizada a metodologia no processo ensino-aprendizagem" (TONON, 2004, p.58).

Os Jogos digitais também proporcionam a união em torno de uma meta, respeitando os pensamentos diferentes em prol de um objetivo comum promovendo a interação social, a cooperação e a colaboração.

\section{Considerações}

Durante anos a matemática foi considerada uma matéria apenas para os gênios, historicamente foi utilizada como uma forma de manutenção da estratificação entre os povos através da segregação "intelectual", foi ensinada de maneira descontextualizada e de maneira enfadonha seguindo um padrão burocrático, porém com 0 desenvolvimento das ciências cognitivas e a 
democratização da informação a disciplina pode ser ensinada de maneira mais agradável e inteligível.

De acordo com as leituras realizadas as aulas de matemática não podem ser reduzidas apenas aos conteúdos científicos, mas também em preparar os discentes de uma forma mais abrangente desenvolvendo suas aptidões para que sejam utilizadas como instrumento na resolução de problemas do cotidiano e adaptados as novas situações.

Ao docente de matemática cabe o papel indispensável no processo de obtenção do conhecimento dos seus discentes, orientando-os na construção e organização das suas ideias e a percepção de que podem ter uma visão macro sempre que possível, incentivando a busca e a criticidade. O professor precisa continuar aprendendo e incentivar seu aluno que aprenda, deve anima-lo, mas o professor que frequenta seminários, palestras, faz diversos cursos e não consegue se fazer entender não vai ser um incentivador dos seus discentes.

Conclui-se que as condições de trabalho, a falta de recursos, a falta de contextualização, o pré-conceito com a matéria decorrente da falta de base causa temor pela disciplina, geram no aluno o desinteresse dificultando ainda mais a tarefa do professor. O apego ao ensino tradicionalista e a utilização apenas do livro didático como única fonte deixam 0 ensino da matemática enfadonho, desinteressante, burocrático e homogêneo, uma vez que não existe uma metodologia que contemple a todos o índice de interesse é pequeno gerando uma seletividade nociva, porém existem perfis e Inteligências que se encaixam a uma determinada metodologia ou apenas o interesse de experimentar um recurso ou estratégia que não precisa ser necessariamente muito planejada como por exemplo na a substituição da variáveis $2 X$ por 2 laranjas ou $2 Y$ por 2 bananas para que 0 aluno entenda que não podem ser somados ou subtraídos pois não são termos semelhantes, não precisa muito basta que o professor tenha empatia e se interesse pelo aluno.

Vale destacar que não adiantam metodologias e estratégias se o discente não estiver aberto para receber o a mensagem que o professor tem para transmitir, ele precisa acabar com o pré-conceito que o discente tem com relação ao aprendizado da matéria e essa é a primeira barreira que deve ser quebrada, de que nem todos estão aptos a aprender a matéria, esse dogma está sendo derrubado e precisa ser divulgado para que todos saibam que a matemática não é impossível, que ela não é 
para poucos mas que sim todos podem aprender, existem estudos que comprovam isso como o da professora, e autora de diversos livros relacionados a aprendizagem em matemática Jo Boaler, ela afirma que todos podem aprender matemática, através de diferentes abordagens, só precisam receber os estímulos certos.

\section{Referências}

BARROS; A. J. da S.; LEHFELD, N. A. de S. Fundamentos de metodologia científica. São Paulo: Pearson Prentice Hall, 2007.

D'AMBROSIO, B. S. Como ensinar matemática hoje. Temas e debates 2.2 Belo Horizonte: Autêntica, 1989.

DANTE, L. R. Didática de resolução de problemas de Matemática. 2. ed. São Paulo: Ática. 1991.

D’AMBROSIO, U. Etnomatemática: elo entre as tradições e a modernidade. 5.ed. Belo Horizonte: Autêntica, 2013.

CUNHA, F.; GOMES FIGUEIREDO, J. A. Estilos de aprendizagem frente aos conteúdos de classificação dos seres vivos baseado no questionário VARK .. Artigos, volume 1. Paraná: Secretaria de Educação, 2016.

FLEMING, N. D. Teaching and learning styles: VARK strategies. Christchurch, New Zealand: N. D. Fleming, 2001.

FREIRE, P. Pedagogia do oprimido. Rio de Janeiro: Editora Paz e Terra. 1987. FREIRE, P. Pedagogia autonomia. Saberes necessários à prática educativa. São Paulo: Editora Paz e Terra, 1996.

FREITAG, B. Sociedade e consciência: um estudo piagetiano na favela e na escola. São Paulo: Cortez, 1984.

INEP. O que é o PISA.C. 2007. Disponível em: http://portal.inep.gov.br/artigo/lasset publisher/B4AQV9zFY7Bv/content/o-que-e-o-pisa/21206. Acesso em: $11 \mathrm{de}$ abr. 2020

KRAKAUER, P. V. C.; SANTOS, S. A.; ALMEIDA, M. I, R. Teoria da Aprendizagem Experiencial no Ensino de Empreendedorismo: Um Estudo Exploratório. Rio de Janeiro: Revista de Empreendedorismo e Gestão de Pequenas Empresas, 2017.

MOURA, M. O. O jogo e a construção do conhecimento matemático. São Paulo: FDE, 1992.

OLIVEIRA, M. M. Como fazer pesquisa qualitativa. Petrópolis, RJ: Ed Vozes, 2007 PEREIRA, D. S. C. 0 ato de aprender e o sujeito que aprende. Constr. psicopedag., São $\quad$ Paulo,. $2010 \quad$ Disponível em<http://pepsic.bvsalud.org/scielo.php?script=sci_arttext\&pid=S1415-

69542010000100010\&lng=pt\&nrm=iso>. acessos em 12 maio 2020.

PIAGET. J. Epistemologia genética. São Paulo: Martins Fontes, 1990.

SANTOS, B. P. Paulo Freire e Ubiratan D'Ambrosio: contribuições para a formação do professor de matemática no Brasil. São Paulo: USP, 2007.

SILVA, S. A; ARAUJO, J. A. A. Maria Montessori e a criação do material dourado como instrumento metodológico para o ensino de matemática nos anos iniciais da escolarização. Nova Andradina-MS: III Simpósio de Educação Matemática de Nova Andradina, n. 1, 2011.

TONON, M. H. H. Matemática: um olhar empático sobre o ensino-aprendizagem. União da Vitória: FACE, 2004. 